Letrônica, Porto Alegre, v. 7, n. 2, p. 522-550, jul./dez., 2014

\title{
PRINCÍPIO DE SALIÊNCIA FÔNICA: ISSO NÃO SOA BEM
}

\author{
PRINCIPLE OF PHONIC SALIENCE: \\ IT DOES NOT SOUND GOOD
}

Raquel Gomes Chaves*

\begin{abstract}
Resumo: No presente trabalho, tratamos do conceito de Saliência fônica, fundamentados nos estudos relativos ao comportamento variável da concordância verbal de terceira pessoa do plural (eles comem $\sim$ eles come $\emptyset$, eles falam eles falaØ) e da redução e/ou desnasalização

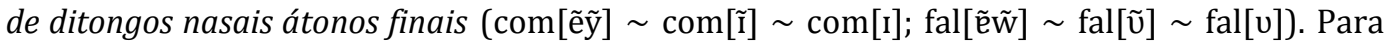
discutir a Saliência fônica, investigamos e confrontamos as posições assumidas frente à variável por Naro e Lemle (1976), Lemle e Naro (1977), Guy (1981), Naro (1981) e Nicolau $(1984,1995)$. Os estudos referidos foram selecionados em virtude de contemplarem ao menos um dos seguintes critérios: (i) terem proposto diferentes definições para a variável (NARO, LEMLE, 1976; LEMLE, NARO, 1977); (ii) terem estabelecido parâmetros diferenciados para a medição hierárquica da Saliência fônica (LEMLE, NARO, 1977; GUY, 1981; NARO, 1981); (iii) terem rejeitado parcial/completamente a variável (GUY, 1981; NICOLAU, 1984, 1995). Na etapa subsequente, assumimos uma postura crítica perante as acepções adotadas pelos estudos, apontando questões obscuras que necessitam de um exame mais acurado. Por fim, acomodamos essa discussão no quadro da Teoria da Variação e Mudança (WLH, 1968; LABOV, 1972, 1982, 1994, 2010), dando especial destaque à intrínseca relação entre a Saliência fônica e os problemas da restrição e da avaliação.

Palavras-chave: Saliência fônica; Concordância verbal de terceira pessoa do plural; Problema da restrição; Problema da Avaliação.
\end{abstract}

\begin{abstract}
In this paper, we deal with the concept of Phonic salience, based on studies about the variable behavior of third person plural verb agreement (eles comem $\sim$ eles come $\emptyset$, ele falam $\sim$ eles fala $\emptyset$ ), and of the reduction and/or desnasalisation of final unstressed nasal diphthongs $(\operatorname{com}[\tilde{e} \tilde{y}] \sim \operatorname{com}[\tilde{I}] \sim \operatorname{com}[\mathrm{I}] ;$ fal[ $\tilde{e} \tilde{w}] \sim \operatorname{fal}[\tilde{\mathrm{v}}] \sim$ fal[u]). In order to discuss Phonic salience, we investigate and confront positions assumed by Naro and Lemle (1976), Lemle and Naro (1977), Guy (1981), Naro (1981) and Nicolau $(1984,1995)$. These studies were selected because they concerned about at least one of the following criteria: (i) they have suggested different definitions for the variable (NARO, LEMLE, 1976; LEMLE, NARO, 1977); (ii) they have proposed singular parameters to measure Phonic salience (LEMLE, NARO, 1977; GUY, 1981; NARO, 1981); (iii) they have rejected partially/completely the principle (GUY, 1981; NICOLAU, 1984, 1995). In the subsequent step, we assume a critical position in front of the conceptions adopted by these studies, pointing obscure issues that require closer examination. Finally, we settle this discussion on the theoretical framework of the Theory of Language Variation and Change (WLH 1968; LABOV, 1972, 1982, 1994, 2010), giving special
\end{abstract}

\footnotetext{
${ }^{*}$ Mestre em Letras pela Pontifícia Universidade Católica do Rio Grande do Sul (PUCRS) e doutoranda em Linguística pela Universidade Federal de Santa Catarina (UFSC) - bolsista CAPES-PROEX. Vinculada ao Projeto Varsul (Variação Linguística na Região Sul do Brasil), agência UFSC. E-mail: quelgchaves@gmail.com
} 
emphasis on the intrinsic relationship between Phonic Salience and the problems of constraint and evaluation.

Keywords: Phonic Salience; Third person plural verb agreement; Constraint problem; Evaluation problem.

\section{Introdução}

A Saliência fônica tem sido apontada pelos estudos que versam sobre o fenômeno variável da marcação explícita da concordância, tanto nominal quanto verbal, como um dos grupos de fatores mais expressivos no condicionamento da variante marcada. De forma mais detalhada, a grande maioria dos trabalhos tem apontado uma correlação positiva entre o grau de saliência fônica e a marcação da concordância, o que faz com que muitos autores atribuam à variável status de princípio geral.

No que tange ao comportamento variável específico da regra de concordância verbal de terceira pessoa do plural (CVP6) no português brasileiro (eles dizem eles $\operatorname{diz} \emptyset$, eles falavam eles falava ), fenômeno sobre o qual nos concentraremos aqui, a variável Saliência fônica, proposta por Naro e Lemle (1976, 1977), em linhas gerais, prediz que, na oposição singular/plural, as formas verbais que apresentam elevada distinção fônica, mensurada por meio de uma escala hierárquica, seriam mais propícias à marcação explícita da pluralidade do que aquelas que apresentam menor grau.

Apesar de a literatura, em geral, apresentar consenso no que diz respeito à relevância da variável no que concerne à marcação da concordância, tanto a formulação conceitual de saliência quanto a disposição escalar das formas verbais foram alvo, especialmente nas décadas de 1970 e 1980, de intenso debate na literatura: (i) Naro (1981), com base nos critérios acento e distinção material, propõe uma configuração para a escala de Saliência fônica diferente da previamente arquitetada por Naro e Lemle (1977); (ii) Guy (1981), por sua vez, questiona, em parte, a hierarquia proposta por Naro (1981), denunciando a interferência do acento na medição dos graus saliência; (iii) Nicolau (1984) sugere novas escalas e, por fim, rejeita o princípio, indicando a irrelevância da variável na análise de seus dados. 
Em vista do cenário inconclusivo suscitado pelos estudos mencionados e do demasiado destaque assumido por essa variável nos estudos que tratam da CVP6 ${ }^{1}$, este trabalho busca dar prosseguimento a essa discussão. Para tal, em primeira instância, revisamos as acepções atribuídas ao termo saliência fônica e às hierarquias de medição da saliência tradicionalmente referidas e/ou adotadas pela literatura (NARO, LEMLE, 1976; LEMLE, NARO, 1977; NARO, 1981; GUY, 1981; NICOLAU, 1984)². Em seguida, problematizamos as propostas escalares apresentadas, explorando, principalmente: (i) o viés analítico, já enfatizado por Guy (1981), gerado pela eleição da categoria acento como um dos parâmetros na delimitação dos graus de saliência; (ii) a inadequação dos critérios (ora ortográficos, ora fonológicos, ora fonéticos) de mensuração da quantidade de material fônico na oposição singular/plural. Por fim, ampliamos essa discussão dentro da perspectiva teórica da Teoria da Variação e Mudança (WLH, 1968; LABOV, 1972, 1982, 1994), enfatizando o problema da restrição e o problema da avaliação.

Exposto o mote de discussão deste artigo, torna-se necessário expor sua organização. Na seção 1, apresentamos uma revisão das propostas escalares de medição da Saliência fônica já aludidas, das alterações sofridas pelas hierarquias, bem como das reflexões levantadas, com base em dados empíricos, pelos autores arrolados. Na Seção 2, dirigimos um olhar crítico às escalas exibidas, promovendo novas discussões a respeito da variável em questão. Na Seção 3, enquadramos o debate em um panorama mais geral, explorando a natureza da Saliência fônica, inerentemente atrelada aos problemas da restrição e da avaliação (WLH, 1968). Por fim, tecemos as considerações finais desta análise.

\section{Escalas de Saliência fônica: o estado da arte}

No que diz respeito às escalas propostas para a medição da Saliência fônica na distinção de formas verbais singulares e plurais referentes à terceira pessoa do plural, é

\footnotetext{
${ }^{1}$ A relevância estatística da variável Saliência fônica, conforme já mencionamos, trata-se de uma constante nos estudos acerca da concordância (tanto nominal quanto verbal) no PB.

${ }^{2}$ A grande maioria dos trabalhos recentes voltados à análise da regra variável de concordância verbal de terceira pessoa do plural no PB (MONGUILHOTT, 2001; NARO, SCHERRE, 2007; MONGUILHOTT, 2009; WELCHEN, 2009; SCHERRE, NARO, 2010) tem adotado a escala de saliência em níveis proposta por Naro (1981). Entretanto, uma parcela menor de estudos (GONÇALVES, 2007; SANTOS, 2008; FARIA, 2013) assume a posição tomada por Nicolau $(1984,1995)$, rejeitando o grupo de fatores e, avaliando, em seu lugar, a influência da variável Constituição morfológica da forma verbal sobre a regra de concordância. Observa-se, na literatura, portanto, duas posições metodológicas divergentes.
} 
possível fazer alusão às de Naro e Lemle (1976), Lemle e Naro (1977), Naro (1981), Guy (1981) e Nicolau $(1984,1995)^{3}$.

A noção de saliência foi introduzida nos estudos sociolinguísticos por Naro e Lemle (1976) a partir da análise de dados de fala de três informantes cariocas, representantes do estrato socioeconômico baixo. Os informantes foram selecionados com base na premissa assumida pelos autores de que, nas classes média e alta, a aplicação da regra de concordância de P6 seria categórica, diferentemente da suposição feita em relação às classes menos elevadas, nas quais a regra se manifestaria variavelmente. Nesse estudo pioneiro, três variáveis independentes foram controladas: (i) Classe morfológica da forma verbal, (ii) Posição de superfície do sujeito (estruturais); e (iii) Grau de formalidade (não estrutural). Segundo os resultados, foi verificada a atuação de um princípio, denominado pelos autores de princípio de saliência, nos três grupos de fatores: no que diz respeito à atuação da variável Classe morfológica da forma verbal, a marcação explícita da concordância verbal de terceira pessoa ocorreu com mais frequência quando a diferença fonética entre as formas verbais singulares e plurais era maior; em relação à variável Posição de superfície do sujeito, a concordância foi verificada em maiores proporções quando o sujeito encontrava-se anteposto ao verbo; e, por fim, no que tange à variável Grau de formalidade, a concordância foi constatada mais habitualmente em situações formais.

Lemle e Naro (1977), dando prosseguimento aos estudos empreendidos em 1976, investigaram a regra variável de concordância nos dados de entrevistas concedidas por 20 informantes cariocas. A partir da proposta desenvolvida anteriormente, os autores buscaram formalizar uma "escala ordenal" de medição da diferença fônica entre as formas verbais singulares e plurais, mais sofisticada do que a concebida anteriormente, assumindo a hipótese de que "o grau de saliência fônica da diferença morfológica entre a forma singular e a forma plural esteja diretamente relacionado com a probabilidade de aplicação da regra de concordância” (LEMLE, NARO,

\footnotetext{
${ }^{3}$ Lemle, Naro (1977); Naro (1981) e Guy (1981) investigaram o processo de marcação explícita da concordância verbal de terceira pessoa do plural com base no mesmo corpus, constituído por entrevistas concedidas por 20 estudantes cariocas integrantes do Movimento Brasileiro de Alfabetização (MOBRAL). Nicolau (1984), por seu turno, investigou o processo ausência de marcas de concordância verbal de terceira pessoa do plural na fala de 32 sujeitos mineiros da capital Belo Horizonte, estratificados em diferentes classes sociais.
} 
1977, p. 20). Com base nessa conjectura, os autores propuseram três categorizações hierárquicas 4 .

Na primeira proposta escalar (old), estabelecida em seis níveis, os autores buscaram, antes do contato com os dados, argumentos linguísticos que pudessem sustentar uma proposta de organização hierárquica. Em linhas gerais, formas que não apresentavam desinência acentuada e pouca distinção material (fala - falam) foram consideradas formas menos salientes, e formas plurais com completa diferenciação em relação à forma singular e acentuadas (é - são), mais salientes. Entretanto, após a análise, os dados não se comportaram como previsto, isto é, não se verificou correlação entre as taxas de CV e a saliência das formas. Em função disso, uma segunda formulação mais detalhada (neo-code), composta por 14 níveis, foi desenvolvida. Mais uma vez, os resultados não foram compatíveis com o esperado, e uma nova escala foi elaborada. $\mathrm{Na}$ terceira hierarquia (neamal), constituída de 10 graus, alguns dos níveis da escala precursora (neo-code) foram, então, amalgamados. O quadro a seguir apresenta, conjuntamente, essas três propostas de medição escalar dos graus de saliência. ${ }^{5}$

\footnotetext{
${ }^{4}$ (i) 1a categorização (nomeada "old"); (ii) 2 ${ }^{\underline{a}}$ categorização (nomeada "neo-code"); (iii) 3ª categorização (nomeada "neamal").

${ }^{5}$ A apresentação das três escalas por Lemle e Naro (1977) não segue a ordem aqui exposta. Os autores, por questões metodológicas, expuseram as escalas na seguinte sequência: 1a categorização (old), 3a categorização (neo-code) e $2^{a}$ categorização (neamal).
} 
Quadro 1: Categorizações hierárquicas dos graus de saliência (Adaptado de LEMLE, NARO, 1977, p. 20-22)

\begin{tabular}{|c|c|c|c|c|c|c|c|c|}
\hline \multicolumn{3}{|c|}{$\begin{array}{l}\text { Categorização } 1 \\
\text { "old" }\end{array}$} & \multicolumn{3}{|c|}{$\begin{array}{c}\text { Categorização } 2 \\
\text { "neo-code" }\end{array}$} & \multicolumn{3}{|c|}{$\begin{array}{c}\text { Categorização } 3 \\
\text { "neamal" }\end{array}$} \\
\hline Nível & Descrição & Ex. & Nível & Descrição & Ex. & Nível & Descrição & Ex. \\
\hline 1 & $\begin{array}{l}\text { verbos regulares. Diferença entre } \\
\text { singular e plural reside em } \\
\text { desinência átona }\end{array}$ & $\begin{array}{l}\text { fala-falam } \\
\text { come- comem }\end{array}$ & 1 & $\begin{array}{c}\text { verbos regulares nos quais a } \\
\text { diferença entre a vogal das } \\
\text { desinências singular e plural } \\
\text { consiste apenas na nasalização. } \\
\text { (MONOSSÍLABOS) }\end{array}$ & vê-vêem & \multirow[t]{2}{*}{1} & \multirow{2}{*}{$\begin{array}{l}\text { verbos regulares nos quais a } \\
\text { diferença entre a vogal das } \\
\text { desinências singular e plural } \\
\text { consiste apenas na } \\
\text { nasalização. }\end{array}$} & \multirow{2}{*}{$\begin{array}{c}\text { vê - vêem } \\
\text { come - comem } \\
\text { constrói - constroem }\end{array}$} \\
\hline 2 & $\begin{array}{l}\text { diferença entre singular e plural } \\
\text { reside numa vogal nasal final } \\
\text { átona }\end{array}$ & $\begin{array}{l}\text { faz-fazem } \\
\text { quer-querem }\end{array}$ & 2 & $\begin{array}{l}\text { verbos regulares nos quais a } \\
\text { diferença entre a vogal das } \\
\text { desinências singular e plural } \\
\text { consiste apenas na nasalização. - } \\
\text { (POLISSÍLABOS) }\end{array}$ & $\begin{array}{c}\text { come - comem } \\
\text { constrói - constroem }\end{array}$ & & & \\
\hline 3 & $\begin{array}{l}\text { sobreposição de raiz e desinência, } \\
\text { com acento }\end{array}$ & $\begin{array}{l}d a ́-d \tilde{a} o \\
\text { está - estão } \\
\text { vai - vão }\end{array}$ & 3 & $\begin{array}{c}\text { forma singular em a átono e } \\
\text { plural em am (na representação } \\
\text { ortográfica) }\end{array}$ & fala-falam & 2 & $\begin{array}{l}\text { forma singular em a átono e } \\
\text { plural em am (na } \\
\text { representação ortográfica) }\end{array}$ & fala-falam \\
\hline 4 & $\begin{array}{c}\text { acento na desinência, diferença } \\
\text { fonológica maior do que simples } \\
\text { nasalização. pretérito perfeito dos } \\
\text { verbos regulares. }\end{array}$ & $\begin{array}{l}\text { falou-falaram } \\
\text { comeu-comeram }\end{array}$ & 4 & $\begin{array}{l}\text { diferença entre o singular e o } \\
\text { plural consiste numa vogal final } \\
\text { átona, possivelmente nasalizada }\end{array}$ & $\begin{array}{l}\text { faz-fazem; } \\
\text { quer-querem }\end{array}$ & 3 & $\begin{array}{c}\text { diferença entre o singular e o } \\
\text { plural consiste numa vogal } \\
\text { final átona, possivelmente } \\
\text { nasalizada }\end{array}$ & $\begin{array}{l}\text { faz-fazem; } \\
\text { quer-querem }\end{array}$ \\
\hline 5 & pretéritos perfeitos irregulares & $\begin{array}{l}\text { foi-foram } \\
\text { teve- tiveram } \\
\text { trouxe- trouxeram } \\
\text { fez-fizeram }\end{array}$ & 5 & $\begin{array}{l}\text { sobreposição de raiz e desinência, } \\
\text { com acento }\end{array}$ & $\begin{array}{l}\text { está - estão } \\
\text { dá - dão }\end{array}$ & 4 & $\begin{array}{l}\text { sobreposição de raiz e } \\
\text { desinência, com acento }\end{array}$ & $\begin{array}{l}\text { está - estão } \\
\text { dá - dão } \\
\text { vai }-v \tilde{a} o\end{array}$ \\
\hline 6 & $\begin{array}{c}\text { Formas inteiramente distintas } \\
\text { para singular e plural }\end{array}$ & $e^{\prime}-s \tilde{o} o$ & 6 & $\begin{array}{l}\text { sobreposição de raiz e desinência, } \\
\text { com acento }\end{array}$ & vai - vão & 5 & $\begin{array}{c}\text { formas totalmente distintas } \\
\text { para singular e plural }\end{array}$ & é-são \\
\hline & & & 7 & $\begin{array}{c}\text { formas totalmente distintas para } \\
\text { singular e plural }\end{array}$ & é-são & 6 & pretéritos perfeitos regulares & $\begin{array}{l}\text { comeu-comeram } \\
\text { falou-falaram }\end{array}$ \\
\hline & & & 8 & pretéritos perfeitos regulares & $\begin{array}{l}\text { comeu - comeram } \\
\text { partiu - partiram }\end{array}$ & 7 & $\begin{array}{c}\text { pretéritos perfeitos } \\
\text { irregulares, com mudança de } \\
\text { acento }\end{array}$ & $\begin{array}{l}\text { trouxe - trouxeram } \\
\text { disse - disseram } \\
\text { fez-fizeram }\end{array}$ \\
\hline & & & 9 & pretéritos perfeitos regulares & falou-falaram & 8 & caso único & foi-foram \\
\hline & & & 10 & $\begin{array}{l}\text { pretéritos perfeitos irregulares, } \\
\text { com mudança de acento }\end{array}$ & $\begin{array}{l}\text { trouxe-trouxeram } \\
\text { disse-disseram }\end{array}$ & 9 & caso único & veio-vieram \\
\hline & & & 11 & $\begin{array}{c}\text { pretéritos perfeitos irregulares, } \\
\text { com mudança de acento }\end{array}$ & $\begin{array}{c}\text { fez-fizeram } \\
\text { teve-tiveram }\end{array}$ & 10 & caso único & era-eram \\
\hline & & & 12 & caso único & foi-foram & & & \\
\hline & & & 13 & caso único & veio-vieram & & & \\
\hline & & & 14 & caso único & era-eram & & & \\
\hline
\end{tabular}


Dentre as três escalas, apenas a terceira (neamal) mostrou-se relevante, isto é, atestou o efeito da saliência sobre a CV. Os resultados relativos à aplicação dessa última proposta encontram-se expressos na Tab. 1 e Fig. 1.

Tabela 1 - Resultados relativos à 3a categorização escalar

\begin{tabular}{|c|c|c|c|c|c|c|}
\hline & & CATEGORIA & EXEMPLOS & APL/TOT & PERC. & PR \\
\hline \multirow{3}{*}{ 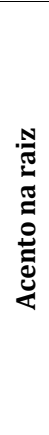 } & & $\begin{array}{c}\text { a) verbos regulares nos quais a } \\
\text { diferença entre a vogal das } \\
\text { desinências singular e plural consiste } \\
\text { apenas na nasalização }\end{array}$ & $\begin{array}{l}\text { come-comem; } \\
\text { constrói- } \\
\text { constroem, vê- } \\
\text { vêem }\end{array}$ & $85 / 626$ & $13,6 \%$ & 0.06 \\
\hline & & $\begin{array}{l}\text { b) forma singular em a átono e plural } \\
\text { em am (na representação ortográfica) } \\
\text { / nasalização e/ou mudança de } \\
\text { qualidade }\end{array}$ & fala-falam & $622 / 2099$ & $29,6 \%$ & 0.17 \\
\hline & & $\begin{array}{l}\text { c) diferença entre singular e plural } \\
\text { consiste em uma vogal átona, } \\
\text { possivelmente nasalizada/ } \\
\text { nasalização e adição de segmento }\end{array}$ & faz-fazem & $124 / 286$ & $43,4 \%$ & 0.27 \\
\hline \multirow{5}{*}{ 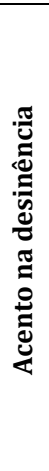 } & \multirow[t]{3}{*}{$\begin{array}{l}\text { Fusão de raiz } \\
\text { e desinência }\end{array}$} & $\begin{array}{l}\text { d) sobreposição de raiz e desinência, } \\
\text { com acento } \\
\text { /nasalização e mudança de qualidade }\end{array}$ & $\begin{array}{l}\text { está - estão, dá- } \\
\text { dão, vai- vão }\end{array}$ & $503 / 768$ & $65,5 \%$ & 0.58 \\
\hline & & $\begin{array}{l}\text { e) Caso único/desinências distintas } \\
(+ \text { consoante })\end{array}$ & foi-foram & $95 / 131$ & $72,5 \%$ & 0.69 \\
\hline & & $\begin{array}{l}\text { f) formas totalmente distintas para } \\
\text { singular e plural distintas }\end{array}$ & $e^{\prime}-s \tilde{a} o$ & $457 / 555$ & $82,4 \%$ & 0.81 \\
\hline & \multirow{2}{*}{$\begin{array}{l}\text { Desinências } \\
\text { separadas da } \\
\text { raiz }\end{array}$} & $\begin{array}{c}\text { g) pretéritos perfeitos regulares/ } \\
\text { desinências distintas }\end{array}$ & $\begin{array}{l}\text { falou-falaram, } \\
\text { comeu-comeram }\end{array}$ & $730 / 897$ & $81,4 \%$ & 0.80 \\
\hline & & h) mudança de acento & $\begin{array}{l}\text { Trouxe- } \\
\text { trouxeram }\end{array}$ & $180 / 201$ & $34,4 \%$ & 0.83 \\
\hline
\end{tabular}

Fonte: LEMLE; NARO (1977, p. 31 e p. 42)

Figura 1: Eixo de saliência proposto por Lemle e Naro (1977)

\begin{tabular}{|c|c|c|}
\hline - salientes & & + saliente \\
\hline $\begin{array}{c}\text { contraste na desinência, } \\
\text { sem acento }\end{array}$ & $\begin{array}{c}\text { contraste na sobreposição raiz - } \\
\text { desinência, com acento }\end{array}$ & $\begin{array}{l}\text { contraste na desinência, } \\
\text { com acento }\end{array}$ \\
\hline$\underbrace{L}$ & $\underbrace{L}$ & $L^{L}$ \\
\hline $\begin{array}{l}\text { 1- come - comem } \\
\text { 2-fala - fala } \\
\text { 3-faz-fazem }\end{array}$ & $\begin{array}{c}\text { 4- está - estão } \\
\text { 5- foi - foram } \\
\text { 6- é - são }\end{array}$ & $\begin{array}{l}\text { 7-falou - falaram } \\
\text { 8- trouxe- trouxeram }\end{array}$ \\
\hline
\end{tabular}

Lemle e Naro (1977, p. 42), ao assumir que a saliência fônica cresce na direção (a) $>$ (h), afirmam que os dados expressos na Tab. 1 atestam a hipótese de que "a falta de concordância ocorre mais freqüentemente naqueles casos em que a diferença entre o singular e o plural é menor, ou menos saliente." 
Em trabalho posterior, fazendo uso dos mesmos dados de Lemle e Naro (1977), Naro (1981), ao identificar o peso da categoria acento na escala precursora, sugere uma nova versão para a hierarquia. Diferentemente da proposta de Lemle e Naro (1977), pautada em uma série de critérios para delimitar o índice de distinção fônica nas oposições verbais singulares e plurais (localização morfológica do acento, quantidade de elementos inseridos na forma plural, alteração da vogal da raiz, grau de distinção das desinências finais, número de sílabas, regularidade das formas e até mesmo modo e tempo verbal), a proposta de Naro (1981) pautou-se em apenas dois parâmetros: (i) presença ou ausência de acento na desinência; (ii) quantidade de material fônico na oposição singular/plural.

Nessa nova hierarquia, a primeira categoria, baseada no critério acento, de natureza mais ampla, é composta por dois planos (Nível 1 - oposição acentuada, Nível 2 - oposição não acentuada). A segunda, por sua vez, centra-se em dois pontos, um qualitativo (alteração/não da qualidade vocálica na desinência, na raiz ou no verbo como um todo) e outro quantitativo (acréscimo/não de segmentos à forma singular). A escala de saliência arquitetada por Naro (1981) encontra-se a seguir.

Quadro 2: Escala de Saliência fônica (Adaptado de NARO, 1981)

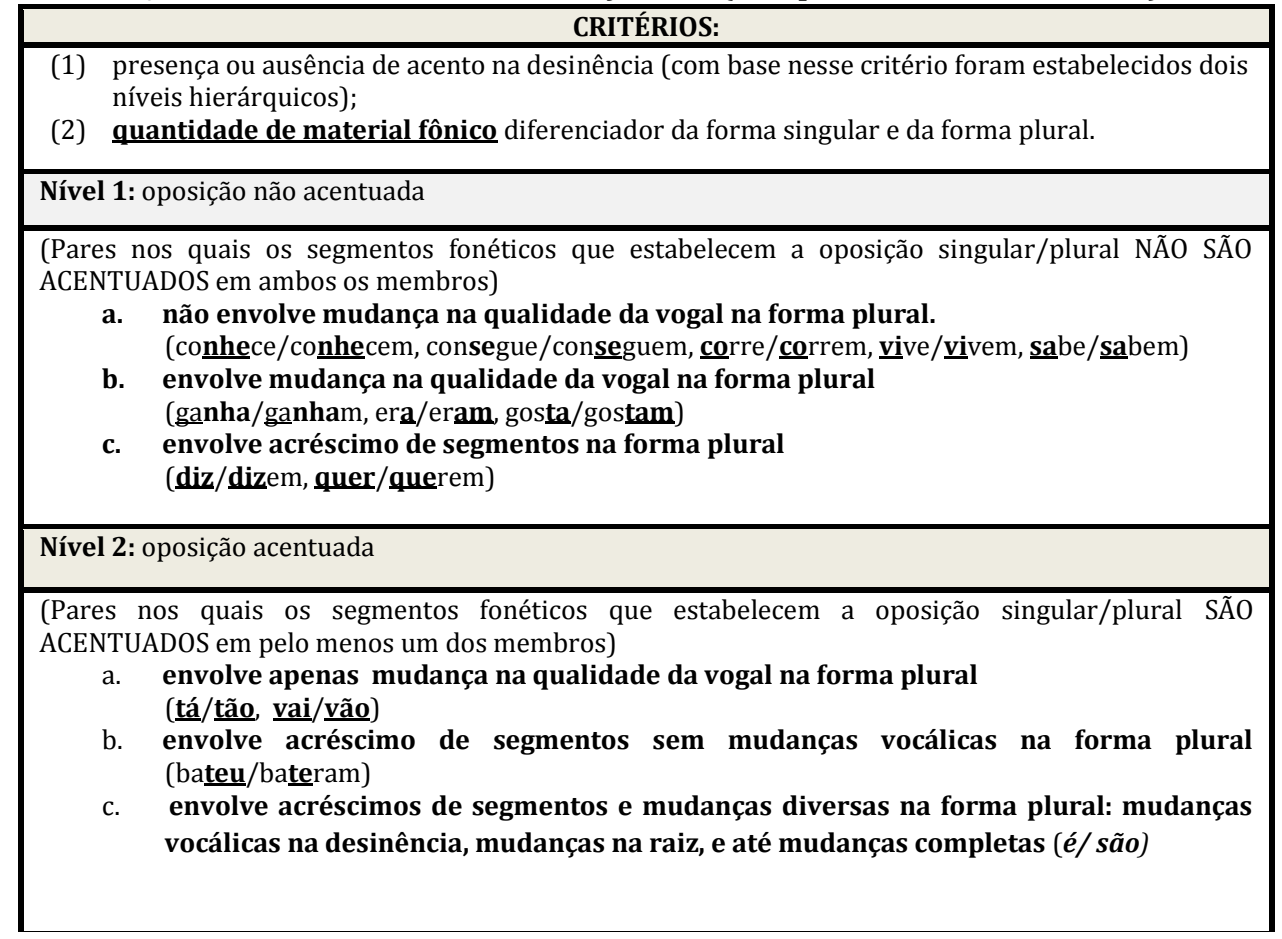


A partir da observação exclusiva das diferenças fonéticas verificadas nas desinências verbais, podemos, com base no esquema proposto também por Naro (1981, p. 75), apresentar a seguinte configuração escalar, equivalente ao Quadro 2.

\section{Nível 1: não acentuado}
a. $[-\mathrm{i} / \mathrm{i}]$
b. $[-\mathrm{a} /-\tilde{\mathrm{u}}]$
c. $[-\varnothing /-\tilde{1}]$

Nível 2: acentuado
a. [-á/-áw]
b. [-éw/-érũ, -íw/-irũ, -óy/-órũ]
c. [-ó/-árũ], [-Ø/-érũ, i/-érũ] e caso único: é/são

Após análise dos dados, fazendo uso dessa nova escala, Naro (1981) atesta a ação da saliência, ao verificar uma correspondência entre maior diferenciação fônica na oposição singular/plural (fosse ela em termos de material fonético ou incidência acentual) e aumento dos índices de marcação da concordância: as formas menos salientes da nova hierarquia (come/comem - [-i/î]) foram as que apresentaram menores taxas de CVP6, e as formas mais salientes, correspondentes a formas verbais tônicas com significativa/completa diferenciação material na oposição singular/plural (falou/falaram - [-ó/-árũ], é - são), as que apresentaram os maiores índices de marcação. A Tab. 2 ilustra esses resultados.

Tabela 2 - Resultados referentes aos Níveis 1 e 2 (Adaptados de NARO, 1981, p. 77)

\begin{tabular}{l|c|c|c|c}
\hline Classificação & Exemplo & Aplicação/Total & Percentual & Probabilidade \\
\hline 1a & come/comem & $110 / 755$ & $14,6 \%$ & 0.11 \\
\hline $\mathbf{b}$ & fala/falam & $763 / 2540$ & $30,0 \%$ & 0.26 \\
\hline c & faz/fazem & $99 / 273$ & $36,3 \%$ & 0.26 \\
\hline 2a & dá/dão & $604 / 927$ & $65,2 \%$ & $\mathbf{0 . 5 8}$ \\
\hline b & comeu/comeram & $266 / 365$ & $72,9 \%$ & $\mathbf{0 . 6 0}$ \\
\hline c & falou/falaram & $1116 / 1450$ & $80,0 \%$ & $\mathbf{0 . 8 5}$ \\
\hline
\end{tabular}

Conforme mostram os resultados da Tab. 2, portanto, a marcação da concordância foi favorecida quando as terminações verbais apresentavam acento na forma singular, na forma plural ou em ambas - dados correspondentes ao Nível 2 da hierarquia. A quantidade de diferenciação material, exposta em ordem crescente em cada um dos dois níveis, Nível $1(\mathrm{a}<\mathrm{b}<\mathrm{c})$ e Nível $2(\mathrm{a}<\mathrm{b}<\mathrm{c})$, também se mostrou relevante à marcação da regra de CV. A tabela consecutiva ilustra os resultados apontados pelo pesquisador, abarcando esses dois critérios (acento e diferenciação material) separadamente. 
Tabela 3 - Resultados referentes aos critérios acento e diferenciação material (Adaptados de NARO, 1981, p. 79)

\begin{tabular}{rl|c|c|c}
\hline \multicolumn{5}{c}{ ACENTO } \\
\hline Classe & Aplicação/Total & Percentual & Probabilidade \\
\hline a) Átonas & $972 / 3568$ & $27,2 \%$ & 0.22 \\
\hline b) Tônicas & $2030 / 2742$ & $74,0 \%$ & $\mathbf{0 . 7 8}$ \\
\hline \multicolumn{5}{c}{ DIFERENCIAÇÃO MATERIAL } \\
\hline Classe & Aplicação/Total & Percentual & Probabilidade \\
\hline a) menor & $714 / 1682$ & $42,4 \%$ & 0.35 \\
\hline b) maior & $1029 / 2905$ & $35,4 \%$ & $\mathbf{0 . 5 4}$ \\
\hline c) completa & $1259 / 1723$ & $73,1 \%$ & $\mathbf{0 . 6 2}$ \\
\hline
\end{tabular}

Guy (1981), em uma nova reanálise dos dados de Lemle e Naro (1977), dedicando-se concomitantemente ao estudo da desnasalização de ditongos nasais átonos finais (homem $\sim$ hom[i], viagem $\sim \operatorname{viag[i],~comem~} \sim \operatorname{com}[\mathrm{i}]$, sabem $\sim \operatorname{sab}[\mathrm{i}]$ ) e da concordância verbal de terceira pessoa do plural (eles comem eles com[i], eles sabem eles sab[i]), exclui da escala de saliência fônica, em um primeiro momento, a categoria que diz respeito aos "presentes regulares" (come - comem, fala - falam), correspondentes aos níveis 1a e 1b na escala de Naro (1981). Nesses verbos, segundo Guy (1981), a pluralidade seria marcada apenas pela nasalização da vogal final. De acordo com o autor, essa exclusão era necessária uma vez que a ausência de marcas de concordância poderia não ser resultado da aplicação da regra de não concordância, mas sim da atuação do processo fonológico de desnasalização.

A possibilidade de sobreposição dos dois fenômenos - um de natureza fonológica e outro de natureza morfossintática - sobre os verbos regulares, revela, segundo Guy (1981), a natureza morfofonológica do fenômeno em questão. Sob esse ponto de vista, o autor questiona se "[...] a hierarquia de oposição de saliência teria maior relevância do que uma simples divisão dos verbos no plural que podem ou não ser convertidos em singular pela desnasalização?"6 (GUY, 1981, p. 255).

A fim de responder a essa indagação, o autor investigou, tomando como ponto de partida o estudo de Votre (1978), nos dados verbais e nominais que apresentavam segmentos nasais átonos finais (falam $\sim$ fala, garagem $\sim$ garage), quais eram os condicionadores estruturais do processo de desnasalização. Dos quatro grupos de fatores controlados (Contexto precedente, Contexto seguinte, Qualidade da vogal alvo e

\footnotetext{
${ }^{6}$ No original: "[...] does the oppositional salience hierarchy have anymore content than a simple division of verbs into those where plural can be converted to singular by desnasalization, and those where it cannot?"
} 
Categoria morfológica da palavra), mostraram-se relevantes: (i) as consoantes palatais e velares em contexto precedente à vogal (ontem $\sim$ onte, garagem $\sim$ garage) e (ii) as vogais altas /i/ e /u/.

Após a investigação do processo de desnasalização em nomes e verbos, Guy (1981), na tentativa de eliminar o viés analítico gerado pela possível sobreposição das duas regras (desnasalização e não concordância) passa a observar apenas os dados verbais. 0 autor decide, então, analisar exclusivamente o comportamento dos verbos que apresentam desinências tônicas na oposição singular/plural e dos verbos que, apesar de apresentarem desinências átonas, exibem outros elementos fonéticos responsáveis pela manutenção da concordância, mesmo com a queda de nasalidade $(f a z$ - fazem $)^{7}$. Em suma, Guy (1981), em primeira instância, investiga apenas os dados sobre os quais, segundo o autor, a não marcação explícita de concordância pode ser atribuída exclusivamente a não aplicação da regra de concordância verbal, conforme mostra o Quadro 3 a seguir.

Quadro 3: Primeira escala de Saliência fônica proposta por Guy (1981, p. 255)

\begin{tabular}{|c|c|c|}
\hline Nível & Descrição & Exemplos \\
\hline 1 & $\begin{array}{l}\text { Formas verbais em que a oposição singular plural se } \\
\text { dá em desinências átonas, mas com inserção de } \\
\text { elementos } \\
{[\emptyset] /[\text { ẽ̃̃] } \sim[\tilde{I}]}\end{array}$ & 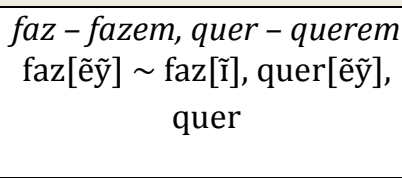 \\
\hline 2 & $\begin{array}{l}\text { 2. Verbos iguais aos regulares exceto pelo fato de } \\
\text { serem acentuados }\end{array}$ & $\begin{array}{l}d a ́-d \tilde{a} o \\
\mathrm{~d}[\tilde{a} \tilde{w}]\end{array}$ \\
\hline 3 & $\begin{array}{l}\text { 3. Formas em que a diferenciação singular/plural se dá } \\
\text { pelo acréscimo de -ram }\end{array}$ & 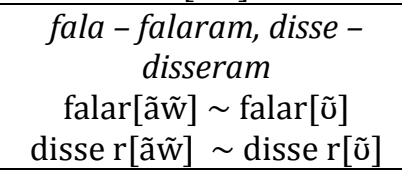 \\
\hline 4 & 4. Formas completamente diferentes & $e ́$-são \\
\hline
\end{tabular}

Os resultados relativos a essa primeira escala ratificam o efeito da saliência, medida aqui apenas com base no critério distinção material, já que os verbos com desinências não acentuadas na oposição singular/plural (verbos regulares) foram eliminados da investigação. Como podemos observar, os índices probabilísticos apresentam crescimento paralelo ao nível de saliência estipulados.

\footnotetext{
${ }^{7}$ Neste caso, há, na forma plural, a introdução da vogal [i] além da nasalidade.
} 
Tabela 4 - Resultados referentes à primeira escala de Saliência fônica (Adaptados de GUY, 1981, p. 256)

\begin{tabular}{cl|c|c}
\hline \multicolumn{2}{c|}{ Categoria } & $\begin{array}{c}\text { \% de marcação de } \\
\text { pluralidade }\end{array}$ & Peso Relativo \\
\hline 1. & faz - fazem & 34 & .14 \\
\hline $2 . \quad$ dá - dão & 64 & $\mathbf{. 5 1}$ \\
\hline 3. & pretéritos & 79 & $\mathbf{. 6 9}$ \\
\hline $4 . \quad$ é - são & 77 &. $\mathbf{7 3}$ \\
\hline
\end{tabular}

Na etapa seguinte, Guy (1981) amplia a escala anterior, desmembrando a categoria "pretéritos" em duas: (a) pretéritos regulares (falou - falaram, sumiu sumiram) e (b) pretéritos irregulares (fez - fizeram, disse - disseram, foi - foram). A hipótese aventada em relação a esses novos fatores foi a de que os pretéritos regulares, por se tratarem de formas com menor saliência na oposição singular/plural (acréscimo de -ram na forma plural), teriam probabilidade inferior de marcação explícita de CV. Entretanto, os resultados não corresponderam ao esperado: os pretéritos regulares exibiram índice percentual de aplicação de concordância de 81\% (.69), enquanto que os irregulares exibiram taxa inferior, equivalente a $73 \%(.58)$.

Apesar de o resultado parecer um contra-argumento ao princípio de saliência, Guy (1981) afirma que tal contradição seria apenas aparente, apontando um fato já apresentado por Naro (1981): haveria uma diferença expressiva entre os pretéritos regulares da primeira conjugação - oposição singular/plural /ów - árãw/ (falou falaram) - e os pretéritos regulares de segunda e terceira conjugação - oposição singular/plural /éw - érãw/; /íw - írãw/ (bebeu - beberam; viu - viram). Nos casos da primeira conjugação, observa-se alteração da vogal temática (/o/ > /a/), enquanto nos casos da segunda/terceira conjugações, a vogal temática se mantém inalterada. Sendo assim, haveria entre essas formas outra diferença em termos de saliência. Ao incorporar essa constatação à hierarquia, os valores percentuais e as probabilidades de aplicação da regra de concordância assumiram a configuração crescente esperada: os pretéritos da segunda e terceira conjugações apresentaram índice percentual de 75\% e peso relativo de .59, e os pretéritos da primeira conjugação, taxa de 82\% e índice probabilístico de .68.

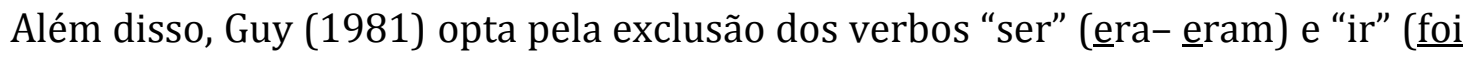
- foram) da categoria pretéritos irregulares, em função de esses verbos, de forma distinta

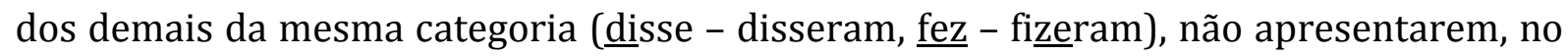
plural, alternância de acento da raiz para a desinência. Com isso, Guy (1981) observa um 
efeito dramático: a nova categoria referente aos verbos excluídos apresentou um percentual de concordância de $61 \%$ e peso relativo de .47 , e a categoria relativa aos verbos irregulares (fez - fizeram, trouxe - trouxeram), a qual apresentava alternância acentual (raiz > desinência), passou a exibir uma taxa de aplicação da regra de 83\% e peso relativo de .64. Dessa forma, Guy (1981) encontra argumentos estruturais, relacionados à distinção fonética, para reorganizar, em sete níveis, a tabela hierárquica de medição da saliência. Os resultados referentes a essa nova organização encontram-se dispostos abaixo.

Tabela 5 - Resultados da hierarquia de Saliência fônica em sete níveis (Adaptados de GUY, 1981, p. 258)

\begin{tabular}{c|c|c}
\hline Categoria & $\begin{array}{c}\text { \% de marcação de } \\
\text { pluralidade }\end{array}$ & Peso Relativo \\
\hline 1. faz - fazem & 34 & .11 \\
\hline $2 . \quad$ dá - dão & 64 & .45 \\
\hline 3. foi - foram & 61 & .47 \\
\hline 4. sumiu - sumiram & 75 &. $\mathbf{5 9}$ \\
\hline $5 . \quad$ falou - falaram & 82 & $\mathbf{. 6 8}$ \\
\hline 6. & pretéritos irreg. & $\mathbf{6 4}$ \\
& com troca \\
acentual & 83 & \\
\hline 7. é - são & &. $\mathbf{6 7}$ \\
\hline
\end{tabular}

Guy (1981, p. 258), todavia, identifica um novo "problema" na escalaridade dos números: o valor probabilístico .68, referente ao fator falou/falaram, viola a hierarquia numérica esperada. Diante do imprevisto, Guy (1981), assumindo novamente a postura adotada por Naro (1981), agrupa as categorias 5 (falou/falaram), 6 (verbos irregulares com troca acentual) e 7 (pretéritos). Essa fusão é justificada em virtude de as diferenças entre as formas singulares e plurais desses verbos, segundo o pesquisador, poderem ser classificadas como "totais", o que, consequentemente, indica um grau "máximo" de saliência em todos esses casos. A hierarquia, assim, passa a ter, nessa versão atualizada, cinco níveis. Os resultados encontrados pelo autor, após o amálgama dos fatores, foram: $1.15<2.51<3.55<4.63<5.70$.

Em função dos valores próximos apresentados pelas categorias 3 (.55) e 4 (.63), Guy (1981), assim como Naro (1981), une-as, caracterizando esse novo fator como aquele em que a desinência no singular é constituída de uma vogal acentuada acrescida de um off-glide e de -ram. 
Desse modo, o autor, ao chegar a essa configuração hierárquica em quatro níveis, reintegra à escala o grupo dos verbos nos quais a "pluralidade pode ser obscurecida ou obliterada pela desnasalização" (tradução nossa) ${ }^{8}$. Após a reinserção, Guy (1981) divide os verbos regulares em duas categorias: (a) verbos que apresentam a vogal /e/ (come comem, sabe - sabem) e (b) verbos que apresentam a vogal /a/ (fala - falam, canta cantam). 0 autor propõe essa separação, pois, com base em Naro (1981), a saliência se manifesta de forma distinta nesses dois tipos de verbos. ${ }^{9}$ Os resultados referentes a essa nova análise encontram-se dispostos na Tab. 6.

Tabela 6 - Resultados da hierarquia de Saliência fônica - inclusão dos verbos regulares (Adaptados de GUY, 1981, p. 260)

\begin{tabular}{c|c|c|c}
\hline \multicolumn{1}{c|}{ Categoria } & $\begin{array}{c}\text { Porcentagem de } \\
\text { marcação de } \\
\text { pluralidade }\end{array}$ & Aplicação/Total & $\begin{array}{c}\text { Peso } \\
\text { Relativo }\end{array}$ \\
\hline 1. $\quad$ come/comem, fale /falem & 14 & $894 / 7.900$ & .15 \\
\hline $2 . \quad$ fala/falam, ia/ iam & 26 & $3161 / 7.900$ & .28 \\
\hline 3. faz/ fazem, quer/querem & 30 & $481 / 7.900$ & .29 \\
\hline $4 . \quad$ dá/dão & 63 & $1112 / 7.900$ & .69 \\
\hline 5. sumiu/sumiram & 66 & $476 / 7.900$ &. $\mathbf{7 6}$ \\
\hline 6. é/são, falou/falaram, & 76 & $1776 / 7.900$ &. $\mathbf{8 4}$ \\
\hline
\end{tabular}

Assim como Naro (1981), Guy (1981) enfatiza que a maior distinção foi observada entre dois grupos: o grupo que compreende as categorias 1-3, no qual as desinências são átonas, e o que compreende as categorias 4-6, no qual as terminações (da forma singular e/ou da forma plural) são tônicas. Ressalta, ainda, o fato de a categoria 3 (faz/fazem) ter apresentado um índice probabilístico de .29, bastante próximo ao da categoria 2 (fala/falam, ia/iam), equivalente a .28, o que, em princípio, não era aguardado. A partir disso, sugere que a não marcação da pluralidade, nesses casos, pode ser resultado, assim como nos verbos pertencentes às categorias 1 e 2 , da atuação exclusiva de processos fonológicos: desnasalização (fazem - fazi) seguida de queda do /i/ final (fazi - fazØ).

Posteriormente, Guy (1981, p. 263) retoma sua indagação inicial, refletindo a respeito da possibilidade de "a hierarquia de saliência indicar apenas que alguns verbos

\footnotetext{
${ }^{8}$ No original: "[...] plurality can be obscured or obliterated by desnasalization" (GUY, 1981, p. 259).

${ }^{9}$ Guy (1981) assume que a oposição entre as formas do singular e do plural nos verbos que apresentam vogal terminal /e/ (come - comem, fale - falem), na variedade popular, pode ser representada por [I] ou [ĩ], diferentemente do que julgam ocorrer na variedade padrão ([I] ou [ẽỹ]), ao passo que na categoria de verbos que apresentam a vogal terminal /a/ (fala - falam, via - viam), a oposição marcadora de pluralidade verificada seria [ã $\tilde{w}]$.
} 
podem ser convertidos em 'singular' por meio da desnasalização [verbos classificados como não acentuados - categorias 1, 2 e 3], enquanto outros não [verbos caracterizados como acentuados - categorias 4, 5 e 6]"10 (tradução nossa). Nos termos do autor:

\begin{abstract}
Mas ainda resta estabelecer se a maior distinção (entre as classes 1-3 e 4-6), que Naro atribui à distinção de saliência entre desinências átonas e tônicas, deve-se a uma restrição real sobre a regra de CV, ou é meramente um reflexo da interferência fonológica resultante da desnasalização ${ }^{11}$ (GUY, 1981, p. 263, tradução nossa).
\end{abstract}

Com base nos resultados expressos na Tab. 6, Guy (1981) encontra fortes indícios de que o efeito mais significativo da saliência provém da (im)possibilidade de aplicação do processo de desnasalização. Em acréscimo, na busca por mais argumentos Guy (1981) incluiu, na análise de seus dados, os condicionadores favorecedores da manifestação da regra fonológica de desnasalização de ditongos nasais átonos finais. Com essa inclusão, o autor supunha que caso os verbos enquadrados nas categorias 1, 2 e 3 (verbos regulares) sofressem de fato a atuação da regra fonológica de desnasalização, os mesmos fatores identificados previamente como cooperadores da aplicação da regra de desnasalização Contexto precedente palatal (palatal ou velar) e Contexto seguinte (vocálico) se mostrassem estatisticamente significativos. Ao mesmo tempo, conjeturava que os demais verbos, com desinências tônicas, categorizados nos níveis 3, 4 e 5, fossem indiferentes aos mesmos grupos de fatores. A partir dessa análise, os seguintes resultados foram vislumbrados:

Tabela 7 - Resultados relativos à atuação das variáveis Contexto precedente e Contexto seguinte nos formas verbais regulares

\begin{tabular}{|c|c|c|c|}
\hline \multicolumn{2}{|c|}{ Contexto precedente } & \multicolumn{2}{|c|}{ Contexto Seguinte } \\
\hline Fator & Peso Relativo & Fator & Peso Relativo \\
\hline Consoante palatal & .43 & $\# \# \mathrm{~V}$ & .38 \\
\hline Vogal & 51 & $=\# \# \mathrm{~K}$ & .51 \\
\hline Outra consoante & .50 & $=\# \#$ & .60 \\
\hline Nasal & .56 & $\# \# \tilde{V}$ & .49 \\
\hline
\end{tabular}

\footnotetext{
${ }^{10}$ No original: "[...] whether salience hierarchy expressed more than the fact that some verbs could be converted to 'singular' by desnasalization, while others could not."

${ }^{11}$ No original: "But it still remains to be established whether the major distinction (between classes 1-3 and 4-6), which Naro attributes to the salience distinction between unstressed and stresse desinences, is due to a real constraint on the SVA rule, or is merely a reflection of the phonological interference resulting from Desnasalization."
} 
Com base nesses valores, Guy (1981) identifica que o contexto precedente consoante palatal (.43) e o contexto seguinte vocálico (.38), apontados como condicionadores da desnasalização, atuam desfavorecendo a marcação da concordância. Tais resultados confirmam a hipótese de que a regra de desnasalização estaria atuando, de fato, sobre os verbos regulares. ${ }^{12}$

Em vista desse resultado, Guy (1981) incluiu também as variáveis Contexto precedente e o Contexto seguinte na análise geral que abarcava tanto os verbos com terminação átona quanto os com terminação tônica com o intuito de verificar o efeito dessa inserção sobre os valores relativos a cada um dos níveis de saliência. Tal interferência mostrou-se bastante significativa, conforme mostra o Quadro 4.

Quadro 4: Resultados das análises com inclusão/exclusão de condicionadores fonológicos

\begin{tabular}{|c|c|c|c|}
\cline { 2 - 4 } \multicolumn{1}{c|}{} & $\begin{array}{c}\text { Categoria } \\
\text { morfológica }\end{array}$ & \multicolumn{2}{c|}{ Probabilidade de marcação do plural } \\
\cline { 2 - 4 } \multicolumn{1}{c|}{} & & $\begin{array}{c}\text { Inclusão dos condicionadores } \\
\text { fonológicos }\end{array}$ & $\begin{array}{c}\text { Exclusão dos condicionadores } \\
\text { fonológicos }\end{array}$ \\
\hline \multirow{2}{*}{ Grupo 1 } & $\mathbf{1}$ & .25 & .15 \\
\cline { 2 - 4 } & $\mathbf{2}$ & .43 & .28 \\
\cline { 2 - 4 } & $\mathbf{3}$ & .44 & .29 \\
\hline \multirow{2}{*}{ Grupo 2 } & $\mathbf{4}$ & .53 & .69 \\
\cline { 2 - 4 } & $\mathbf{5}$ & .62 & .76 \\
\cline { 2 - 4 } & $\mathbf{6}$ & .73 & .84 \\
\hline
\end{tabular}

Fonte: GUY (1981, p. 266)

Como se pode observar, a inclusão das variáveis fonológicas provocou uma redução significativa no que diz respeito às distâncias, em termos de valores probabilísticos, entre as categorias. Assim, não observamos mais uma ruptura drástica entre o comportamento do grupo 1 (categorias 1, 2 e 3) e do grupo 2 (categorias 4, 5, e 6), divisão tão destacada pelas escalas anteriores. Com base nessa verificação, Guy (1981, p. 267) conclui que "parece que 'saliência fônica' é uma restrição sobre a CV um pouco menos importante do que já havíamos suposto previamente"13 (tradução nossa)

Por fim, o pesquisador, ao constatar que o processo fonológico de desnasalização de ditongos nasais átonos finais é bloqueado em ambientes tônicos, e, portanto, passível de atuação apenas nas categorias 1, 2 e 3 (verbos regulares), indica que "das duas

\footnotetext{
12 Vale lembrar que a desnasalização geraria, nesses casos, o mesmo resultado da não aplicação da regra de concordância. Desse modo, os condicionadores que favorecem a desnasalização seriam aqueles que desfavorecem a concordância, fato que guia uma leitura "invertida" dos valores expressos na Tab. 7.

${ }^{13}$ No original: "It would appear that 'oppositional salience' is somewhat less important a constraint on SVA than we have previously supposed." (GUY, 1981, p. 267).
} 
dimensões para a oposição da saliência proposta por Naro [acento e diferenciação material], apenas a menor, diferenciação material, seria um condicionador independente na CV14." Diante disso, o autor recusa o critério acentual, categoria mais genérica da escala de saliência desenvolvida por Naro (1981), na qual formas verbais com desinências tônicas são contrapostas a formas com desinências átonas, considerando essa divisão inapropriada. Conclui, portanto, que o comportamento diferenciado dos verbos racionados nessas duas categorias seria apenas resultado da distinção "entre verbos nos quais o plural pode ser convertido em singular via processo fonológico de desnasalização, e aqueles em que a desnasalização não pode produzir esse efeito."15 (GUY, 1981, p. 268, tradução nossa).

Por fim, Nicolau $(1984,1995)$, na investigação do processo de não concordância verbal de terceira pessoa do plural na fala de Belo Horizonte (MG), parte da hipótese contrária a dos autores referidos até aqui de que "a frequência da aplicação/não da Regra (1) [regra de concordância verbal] não é diretamente proporcional ao grau de saliência fônica [...]" (NICOLAU, 1995, p. 51). Para isso, com base nas escalas anteriores, a autora busca encontrar suporte para sua proposição formulando uma nova, estratificada em 12 níveis, a qual exibimos a seguir.

Quadro 5: Escala de Saliência fônica em 12 níveis (Adaptada de NICOLAU, 1995, p. 52)

\begin{tabular}{|c|c|c|}
\hline $\begin{array}{c}\text { Nível de } \\
\text { saliência fônica }\end{array}$ & $\begin{array}{l}\text { Diferenças fônicas } \\
\text { (sing/plural) }\end{array}$ & Exemplos \\
\hline 1 & {$[-\mathrm{e} /-\tilde{\mathrm{e}} \tilde{\mathrm{w}}]$} & fala; falam/ falava; falavam \\
\hline 2 & {$[-\mathrm{i} /$-ẽ̃y] } & come; come $\underline{\mathbf{m}} /$ fale; fale $\underline{\mathbf{m}}$ \\
\hline 3 & $\varnothing /[-\tilde{e} \tilde{y}]$ & faz; Fazem/fazer; fazerem \\
\hline 4 & {$[-\mathrm{-e} / \mathrm{E} \tilde{\mathrm{w}} \tilde{w}]$} & dá; dãâ/ está; est $\underline{a ̃ o} /$ falará; falarão \\
\hline 5 & 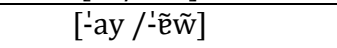 & vai; vâa \\
\hline 6 & {$[-\mathrm{w} /-\mathrm{r} \tilde{e} \tilde{\mathrm{w}}]$} & $\begin{array}{l}\text { morreu; morreram/ partiu; } \\
\text { partiram }\end{array}$ \\
\hline 7 & [-ow / [a.rẽ w̃] & falou/falaram \\
\hline 8 & 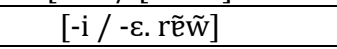 & soube; souberam/ disse; disseram \\
\hline 9 & 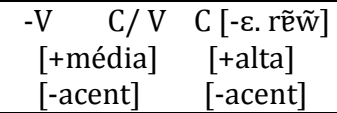 & fez; fizeram/ pôs; puseram/teve; \\
\hline 10 & {$[-y /-r \tilde{e} \tilde{w}]$} & foi; foram \\
\hline 11 & [-is / -jze rẽ $\tilde{w}]$ & quis; quiseram \\
\hline 12 & formas distintas & é; são \\
\hline
\end{tabular}

\footnotetext{
${ }^{14}$ No original: "[...] we conclude that, of the two dimensions for oppositional salience proposed by Naro, only the minor one, material difference, is a separate constraint on SV." (GUY, 1981, p. 268)

${ }^{15}$ No original: "[...] those verbs whose plurals can be converted to superficial singulars via the phonological process of desnasalization, and those whose desnasalization cannot have this effect." (GUY, 1981, p. 268)
} 
A variável, configurada dessa forma, assim como acreditava a autora, não desempenhou papel relevante no processo de não concordância. Das variantes dispostas hierarquicamente em 12 níveis, na primeira rodada estatística, apenas três desempenharam papel favorecendo a não marcação da concordância: (i) fala - falam (.88), (ii) come - comem (.89); (iii) faz - fazem (.85). Tal resultado vai ao encontro dos apontados por Lemle e Naro (1977), Naro (1981) e Guy (1981), estudos nos quais as marcas explícitas da concordância foram verificadas em menor grau nesses contextos, também organizados como os primeiros elementos componentes da escala de saliência fônica. Entretanto, Nicolau (1984), assim como já havia enfatizado Guy (1981), atenta para a semelhança entre esses três fatores: em todos eles, o locus da oposição singular/plural ocorre em terminações átonas, o que torna o ambiente suscetível à aplicação das regras de redução e desnasalização.

No tocante aos demais níveis da escala, não foi possível verificar um comportamento decrescente dos valores probabilísticos ${ }^{16}$. Nas palavras de Nicolau (1995, p. 54), "esses primeiros resultados obtidos não confirmam o PSF [Princípio da Saliência Fônica], estabelecido por NARO e LEMLE (1977) para explicar a ACV [Ausência de Concordância Verbal], pois os valores atribuídos aos fatores considerados não aparecem, como deveriam aparecer, caso esse PSF estivesse atuando - em ordem decrescente [...]", conforme mostra o Quadro 6.

Quadro 6: Resultados referentes à variável Saliência fônica em relação ao processo de não concordância (adaptado de NICOLAU, 1984, p. 109)

\begin{tabular}{|c|c|c|c|c|c|c|c|}
\hline \multicolumn{2}{|l|}{$\begin{array}{c}\text { Nicolau } \\
(1984)\end{array}$} & \multicolumn{2}{|c|}{ Lemle e Naro (1977) } & \multicolumn{2}{|c|}{$\begin{array}{c}\text { Naro } \\
\text { (1981) }\end{array}$} & \multicolumn{2}{|l|}{$\begin{array}{c}\text { Guy } \\
(1981)\end{array}$} \\
\hline fala/falam & .88 & come/comem & .94 & come/comem & .89 & come/comem & .85 \\
\hline come/comem & .89 & fala/falam & .83 & fala/falam & .74 & fala/falam & .72 \\
\hline faz/fazem & .85 & faz/fazem & .73 & faz/fazem & .65 & faz/fazem & .71 \\
\hline dá/dão & .39 & dá/dão & .42 & dá/dão & .32 & dá/dão & .31 \\
\hline vai/vão & .49 & foi/foram & .31 & vai/vão & .22 & $\begin{array}{l}\text { sumiu/sumiram } \\
\text { (foi/foram) }\end{array}$ & .24 \\
\hline $\begin{array}{l}\text { comeu/comeram } \\
\text { falou/falaram } \\
\text { fez/fizeram } \\
\text { foi/foram } \\
\text { é/são }\end{array}$ & $\begin{array}{l}.33 \\
.19 \\
.10 \\
.51 \\
.28\end{array}$ & $\begin{array}{l}\text { é/são } \\
\text { pret. regulares } \\
\text { pret. } \\
\text { irregulares }\end{array}$ & $\begin{array}{l}.19 \\
.20 \\
.17 \\
\end{array}$ & falou/falaram & .15 & $\begin{array}{l}\text { falou/falaram } \\
\text { fez/fizeram } \\
\text { é/ são }\end{array}$ & .16 \\
\hline
\end{tabular}

\footnotetext{
${ }^{16}$ No estudo de Nicolau (1984), esperava-se que, caso o efeito da saliência fosse confirmado, os valores probabilísticos decrescessem, diferentemente do foi verificado nos demais estudos revisados. Isso porque a autora investigou como variável dependente a não marcação da concordância verbal de terceira pessoa. Em outros termos, a hipótese aventada em relação à hierarquia de saliência seria a de os verbos menos salientes apresentariam valores maiores de não marcação do que os verbos mais salientes.
} 
A partir desses resultados, a autora buscou elaborar uma nova configuração da hierarquia, a fim de diminuir a quantidade de graus de saliência. Dessa forma, Nicolau (1984, 1995) procedeu ao amálgama dos fatores que apresentaram índices probabilísticos próximos e semelhanças de ordem estrutural. Os três primeiros níveis da escala de saliência anterior (fala/falam, come/comem, faz/fazem) foram agrupados em um único fator e os que ocupavam a sétima e a oitava posições também foram agregados. Os resultados dessa nova análise encontram-se na Tab. 8 a seguir.

Tabela 8 - Resultados referentes à escala de Saliência fônica em oito níveis

\begin{tabular}{ll}
\hline Categoria & PR \\
\hline fala/falam, come/comem, faz/fazem & $\mathbf{. 9 2}$ \\
dá/dão &. $\mathbf{5 2}$ \\
vai/vão & $\mathbf{. 6 2}$ \\
comeu/comeram, falou/falaram, partiu, partiram & .49 \\
fez/fizeram & .10 \\
foi/foram &. $\mathbf{5 2}$ \\
é/são & .30 \\
\hline
\end{tabular}

Fonte: NICOLAU (1984, p. 110)

Como mais uma vez a autora não encontra, nos resultados, respaldo para assegurar o Princípio da Saliência Fônica e, por ter conhecimento do trabalho de Guy (1981), o qual, em um primeiro momento, exclui os verbos regulares da análise, Nicolau $(1984,1995)$ opta por organizar essa hierarquia em apenas duas categorias: (i) verbos regulares e (ii) verbos irregulares. Ao tomar essa providência, o comportamento de todas as variáveis estruturais sofreu sensível alteração, conforme podemos observar a seguir.

Tabela 9 - Resultados relativos ao comportamento de verbos regulares e irregulares (Adaptados de NICOLAU, 1984, p. 112)

\begin{tabular}{|c|c|c|c|}
\hline Grupo de fatores & Fatores & $\begin{array}{c}\text { Prob. Ausência de CV } \\
\text { verbos regulares }\end{array}$ & $\begin{array}{l}\text { Prob. Ausência de CV } \\
\text { verbos não regulares }\end{array}$ \\
\hline \multirow{3}{*}{$\begin{array}{l}\text { Ambiente fonológico } \\
\text { que sucede ao verbo }\end{array}$} & vogal & .58 & .49 \\
\hline & consoante & .47 & .54 \\
\hline & pausa & .45 & .47 \\
\hline \multirow{6}{*}{$\begin{array}{l}\text { Posição do SN sujeito } \\
\text { em relação ao verbo }\end{array}$} & imediatamente anteposto & .30 & .31 \\
\hline & anteposto e distante & .32 & .29 \\
\hline & expresso em oração & .69 & \\
\hline & anterior & & .41 \\
\hline & posposto & .69 & .88 \\
\hline & $\begin{array}{l}\text { SN constituído de } \\
\text { substantivo }\end{array}$ & .52 & .47 \\
\hline \multirow[t]{3}{*}{$\begin{array}{l}\text { Constituição } \\
\text { sujeito }\end{array}$} & $\begin{array}{l}\text { SN constituído de pronome } \\
\text { pessoal }\end{array}$ & .38 & .35 \\
\hline & $\begin{array}{l}\text { SN constituído de outros } \\
\text { pronomes ou numeral }\end{array}$ & .48 & .46 \\
\hline & $\begin{array}{l}\text { SN constituído de pronome } \\
\text { relativo }\end{array}$ & .62 & .71 \\
\hline
\end{tabular}


Conforme podemos notar na Tab. 9, no que diz respeito à atuação da variável Ambiente fonológico que sucede ao verbo, a ausência de marca de pluralidade foi favorecida nos verbos regulares pelas vogais situadas imediatamente após os verbos e, nos verbos não regulares, as consoantes foram apontadas como colaboradoras da não marcação. No que se refere à variável Posição do SN sujeito em relação ao verbo, os fatores expresso em oração anterior e posposto mostraram-se relevantes à ausência de marcas de concordância nos verbos regulares, entretanto, apenas o fator posposto mostrou-se significativo na análise relativa aos verbos não regulares. Por fim, apenas em relação à última variável, Constituição do SN sujeito, foi verificado favorecimento semelhante nos dois grupos verbais: o fator SN constituído de pronome relativo mostrouse cooperador da ausência de marcas de concordância nos verbos regulares e não regulares. Apesar dessa semelhança, vale ressaltar que os valores probabilísticos correspondentes à atuação dessa variável sobre os verbos regulares (.62) e irregulares (.71) ainda se mostraram bastante distantes.

Assim como Guy (1981), Nicolau (1984, 1995) busca verificar em seus dados a atuação do Princípio de Saliência observando apenas os itens verbais irregulares, já que indica também efeito do processo fonológico de desnasalização sobre os verbos regulares. Adaptando os resultados expostos por Nicolau $(1984,1995)$, são apontados, de forma bastante próxima ao que foi vislumbrado nos dados apresentados por Guy (1981, p. 256), como desfavorecedores da não concordância (favorecedores, portanto, da CV) as seguintes categorias: (i) fez/fizeram (.25); (ii) é/são (.37); (iii) falou/falaram (.43) e (iv) dá/dão (.49). Tais níveis coincidem exatamente com os três últimos níveis apontados por Guy (cf. Tab. 6) como categorias identificadas como mais salientes e como aquelas que mais contribuem com a marcação da concordância. Sendo assim, de forma análoga a Guy (1981), apesar de Nicolau $(1984,1995)$ rejeitar a variável Saliência fônica, apontando a relevância, em seu lugar, da variável Constituição morfológica verbal, é possível encontrar, nos resultados apresentados pela autora, argumentos em prol do critério "diferenciação material" na constituição da escala de saliência. Em suma, Guy (1981) e Nicolau $(1984,1995)$ incitam reflexões em relação às escalas de saliência de Naro e Lemle (1976), Lemle e Naro (1977) e Naro (1981). Essas e outras novas questões serão debatidas na próxima seção. 


\section{Apreciação crítica da variável Saliência fônica}

Antes de discutirmos alguns pontos levantados na seção anterior, cabe refletir sobre a acepção original do termo saliência. Nos estudos precursores acerca da CVP6 (NARO, LEMLE, 1976; LEMLE, NARO, 1977), observa-se uma nítida relação entre a concepção de saliência e o sentido literal da expressão, designada como "parte mais elevada que se destaca em uma superfície lisa" (HOUAISS, 2004, p. 661). Nessa primeira noção fazia-se, portanto, referência àquilo que seria mais proeminente e, consequentemente, mais perceptível aos sujeitos. ${ }^{17} \mathrm{Em}$ outros termos, nos parece que, nesse primeiro uso do termo, os contextos apontados como significativos a não aplicação da regra de concordância (verbos regulares, sujeitos pospostos, situações informais) seriam menos salientes (isto é, menos marcados) no sentido de não gerarem, como nos demais ambientes, estranhamento.

Entretanto, ao revisarmos as escalas de saliência, tal concepção parece não ter sido contemplada, visto que as hierarquias foram estabelecidas não com base em critérios delimitados pela percepção da saliência, mas sim em parâmetros de ordem linguística, internos ao sistema. A partir disso, o questionamento que se coloca é: critérios linguísticos, por si só, determinam o grau de saliência na oposição de singular/plural?

Com base na revisão apresentada, encontramos argumentos tanto para uma resposta afirmativa - se pensarmos na semelhança entre os resultados apresentados por Guy (1981) e Nicolau (1984) -, como negativa - se pensarmos nas diferenças em termos probabilísticos apresentadas pelos estudos aludidos, os quais muitas vezes sugeriram alterações nas propostas hierárquicas em virtude da não verificação de correlação positiva entre aumento da saliência e aumento das taxas de CV.

Secundariamente, fazendo um diagnóstico ainda que holístico dos critérios linguísticos delimitados para o estabelecimento das hierarquias de saliência, observamos outra questão que merece igualmente atenção: o que significa maior quantidade de material fonético? Como mensurá-la? Na proposta de Lemle e Naro (1976, 1977), torna-se complexo identificar qual dos parâmetros delimitados (acento,

\footnotetext{
17 Podemos pensar que, nessa primeira proposta, apontar uma estrutura como saliente significaria, em termos informais, assumir que tal forma "não soa bem". A noção de avaliação, no caso, negativa, portanto, estaria agregada a essa concepção.
} 
quantidade material fônico, número de sílabas, alterações na raiz etc.) seria responsável pelas distinções nos graus de saliência e, principalmente, qual seria a justificativa para a formulação de uma hierarquia.

Apesar de observarmos uma melhor organização dos critérios propostos na hierarquia de Naro (1981), dividida em duas categorias macro (formas acentuadas e formas não acentuadas) e subdividida em níveis inferiores (distinção de material fônico), é importante ressaltar que a "régua" empregada na mensuração da distinção material ainda é nebulosa. 0 ponto de partida para o estabelecimento da diferença material das formas, expresso no Quadro 7, já nos dá indícios do quão escorregadia é essa mensuração.

Quadro 7: Esquema das possíveis dimensões da mudança sintática

(Adaptado de NARO, 1981, p. 65)

\begin{tabular}{|c|c|c|c|}
\hline CLASSE & FORMA ORTOGRÁFICA & VARIANTE POPULAR & VARIANTE PADRÃO \\
\hline \multicolumn{4}{|c|}{ I) PRESENTE } \\
\hline $\begin{array}{l}\text { 1a conjugação } \\
\text { (regular) }\end{array}$ & $\begin{array}{l}\text { sing. fala } \\
\text { plur. fal } \underline{\underline{a} \boldsymbol{m}}\end{array}$ & $\begin{array}{c}{[-\mathrm{a}]} \\
{[-\tilde{u},-\mathrm{u},-\tilde{a}]}\end{array}$ & $\begin{array}{c}{[-\mathrm{a}]} \\
{[-\tilde{a} \tilde{w}]}\end{array}$ \\
\hline $\begin{array}{l}2^{2} \text { e } 3^{\underline{a}} \text { conjugação } \\
\text { (regular) }\end{array}$ & $\begin{array}{l}\text { sing. parte } \\
\text { plur. partem }\end{array}$ & $\begin{array}{l}{[-\mathrm{i}]} \\
{[-1 \overline{]}]} \\
\end{array}$ & $\begin{array}{c}{[-\mathrm{i}]} \\
{[-\tilde{e} \tilde{y}]}\end{array}$ \\
\hline $\begin{array}{l}2^{\text {a }} \text { e } 3^{\underline{a}} \text { conjugação } \\
\text { (-r ou }-z)\end{array}$ & $\begin{array}{l}\text { sing. faz } \\
\text { plur. } f a z \underline{\text { em }}\end{array}$ & $\begin{array}{c}\varnothing \\
{[-\tilde{\imath},-i]}\end{array}$ & $\left.\begin{array}{c}\varnothing \\
{[-\tilde{e} \tilde{y}]}\end{array}\right]$ \\
\hline Monossílabos & $\begin{array}{l}\text { sing. } d \underline{\underline{a}} \\
\text { plur. } d \underline{\underline{\tilde{a}}} \underline{\underline{o}}\end{array}$ & $\begin{array}{c}{[-\mathrm{a}]} \\
{[-\tilde{a} \tilde{w}]} \\
\end{array}$ & $\begin{array}{c}{[-\mathrm{a}]} \\
{[-\tilde{a} \tilde{w}]}\end{array}$ \\
\hline \multicolumn{4}{|c|}{ II) PRETÉRITO IMPERFEITO } \\
\hline Todos os verbos & $\begin{array}{l}\text { sing. falava } \\
\text { plur. falava } \underline{\underline{a}}\end{array}$ & $\begin{array}{c}{[-\mathrm{a}]} \\
{[-\tilde{u},-\mathrm{u},-\tilde{a}]} \\
\end{array}$ & $\begin{array}{c}{[-\mathrm{a}]} \\
{[-\tilde{a} \tilde{w}]}\end{array}$ \\
\hline \multicolumn{4}{|c|}{ III) FUTURO } \\
\hline Todos os verbos & $\begin{array}{l}\text { sing. falará } \\
\text { plur. falarẫo }\end{array}$ & $\begin{array}{c}{[-\mathrm{a}]} \\
{[-a \tilde{w}]} \\
\end{array}$ & $\begin{array}{c}{[-a]} \\
{[-a \tilde{w}]}\end{array}$ \\
\hline \multicolumn{4}{|c|}{ IV) PRETÉRITO PERFEITO } \\
\hline $\begin{array}{l}\text { 1'a conjugação } \\
\text { (regular) }\end{array}$ & $\begin{array}{l}\text { sing. falou } \\
\text { plur. falaram }\end{array}$ & $\begin{array}{c}{[-\mathrm{o}]} \\
{[-\operatorname{aru}, \text {-aru] }}\end{array}$ & $\begin{array}{l}{[-0,-o w]} \\
{[-a r a \tilde{w}]}\end{array}$ \\
\hline $\begin{array}{l}\text { 20 e } 3^{\text {a }} \text { conjugação } \\
\text { (regular) }\end{array}$ & $\begin{array}{l}\text { sing. aprendeu } \\
\text { plur. aprenderam }\end{array}$ & $\begin{array}{c}{[-\mathrm{ew}]} \\
\text { [-erũ, -eru] }\end{array}$ & $\begin{array}{c}{[-\mathrm{ew}]} \\
{[-\mathrm{erãa} w]}\end{array}$ \\
\hline $\begin{array}{l}2^{\mathbf{a}} \text { e } 3^{\mathrm{a}} \text { conjugação } \\
\text { (regular) }\end{array}$ & $\begin{array}{l}\text { sing. partiu } \\
\text { plur. partiram }\end{array}$ & $\begin{array}{c}{[-\mathrm{iw}]} \\
{\left[-\mathrm{iru},{ }^{-}-\mathrm{iru}\right]}\end{array}$ & $\begin{array}{c}{[-i w]} \\
{[-i r a \tilde{w}]}\end{array}$ \\
\hline $\begin{array}{l}\text { alternância - acentual } \\
\text { (irregular) }\end{array}$ & $\begin{array}{l}\text { sing. trouxe } \\
\text { plur. trouxeram }\end{array}$ & {$[-\mathrm{i}]$} & [érãw] \\
\hline $\begin{array}{l}\text { mudança no radical } \\
\text { (irregular) }\end{array}$ & $\begin{array}{l}\text { sing. fezz } \\
\text { plur. } f \underline{z} z e r a m\end{array}$ & $\begin{array}{c}\varnothing \\
\text { [-erũ, -eru] }\end{array}$ & $\begin{array}{c}\varnothing \\
\text { [-erãw] }\end{array}$ \\
\hline
\end{tabular}

Naro (1981), nesse esquema, indica que a presença do ditongo nasal átono final [ãw] seria a marca categórica de pluralidade na variedade padrão carioca e, ao mesmo tempo, assume que tal forma nunca é verificada na variedade popular. Tal fato causa desconforto visto que muitos trabalhos, dentre os quais é possível fazer referência aos 
de Monguilhott (2009) e Welchen (2009), têm indicado comportamento variável das formas fonéticas [ã̃̃], [ũ] e [u] em ambas as variedades.

Partindo disso e com base na premissa de que a fonética ${ }^{18}$ não lida com oposições abstratas (papel destinado à fonologia), verifica-se uma contradição nas propostas escalares de medição da saliência fônica. Os autores parecem sugerir, ao estabelecer uma escala fixa de mensuração da oposição singular/plural, que haveria uma única forma subjacente compartilhada entre os sujeitos. Em outros termos, ao assumirem que o verbo come teria menor grau de saliência do que o verbo falam, deixam de considerar a produção real dos falantes, as quais poderiam reverter os valores hierárquicos de saliência: um falante, ao produzir fal[v] (marcando a concordância com a redução do ditongo, perda da nasalidade) diminuiria o grau de saliência (fala - falu), visto que haveria apenas alteração da qualidade da vogal ([e] - [v]), e, ao produzir com[ẽỹ] (marcando a concordância com ditongo nasal átono final), por exemplo, elevaria o grau de saliência (come - comẽỹ), já que, neste caso, teríamos o acréscimo de uma semivogal [y] e do traço de nasalidade.

Caso a fonética fosse realmente delimitada como critério para medição dos graus de saliência, nossa primeira alternativa seria a formulação de uma nova configuração escalar, a qual deveria abarcar na comparação singular/plural todas as possibilidades de produção, como nos casos expressos abaixo referentes aos verbos no pretérito imperfeito do indicativo.

Quadro 8: Hipotetização das realizações fonéticas dos verbos pretérito imperfeito do indicativo (singular/plural)

\begin{tabular}{|c|c|c|}
\hline \multicolumn{3}{|c|}{ Variantes "morfofonéticas" - pretérito imperfeito do indicativo } \\
\hline \multicolumn{3}{|c|}{ SEM MARCAS EXPLÏCITAS DE CONCORDÂNCIA DE NÜMERO } \\
\hline opinav [e] & aprendi[e] & nutri $[\mathrm{e}]$ \\
\hline \multicolumn{3}{|c|}{ COM MARCAS EXPLÍCITAS DE CONCORDÂNCIA DE NÚMERO } \\
\hline 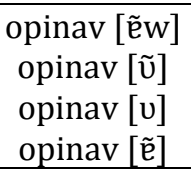 & 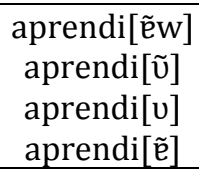 & $\begin{array}{c}\text { nutr[ẽj] } \\
\text { nutr[Ĩ] } \\
\text { nutr[ẽ] }\end{array}$ \\
\hline
\end{tabular}

Em acréscimo, é essencial enfatizarmos o fato, corroborado por Guy (1981), de que o parâmetro acentuação, critério estabelecido para a divisão em níveis da tabela de saliência proposta por Naro (1981), empregada majoritariamente em trabalhos sociolinguísticos, possa estar contribuindo para a demasiada relevância da variável. Esse

\footnotetext{
${ }^{18}$ Critério com o qual todos os autores se comprometem na elaboração das escalas de Saliência fônica.
} 
fato é confirmado ao observarmos os resultados dos estudos que optam pela tabela proposta por Naro (1981), a variável Saliência fônica é geralmente apontada como um dos fatores mais significativos à aplicação da regra de concordância verbal.

A nosso ver torna-se fundamental, portanto, incorporar as contribuições de Guy (1981) às escalas de saliência fônica empregadas nos estudos atuais, considerando que a divisão em níveis formulada por Naro (1981) não estaria opondo formas acentuadas (+ salientes) a formas não acentuadas (- salientes), mas sim formas suscetíveis ou não à aplicação do processo de desnasalização. Em outros termos, como os primeiros estudos referentes à análise dos processos de redução e desnasalização de ditongos nasais átonos finais no PB (VOTRE, 1978; GUY, 1981) destacaram, o processo de desnasalização é que sofre influência direta do acento, visto que se observa a preservação categórica tanto dos ditongos quanto das nasais em ambientes tônicos. Sendo assim, considerar a categoria acento como um dos quesitos para mensurar o grau de saliência e, consequentemente, apontá-lo como fator colaborador da marcação da concordância trata-se, a nosso ver, uma conclusão, em parte, equivocada.

\section{A Saliência fônica e os problemas da restrição e da avaliação}

Uma das preocupações seminais da Teoria da Variação e Mudança (WLH, 1968), retratada pelo problema da restrição é a de identificar convergências e generalidades no comportamento de diversos sistemas linguísticos. A busca por similaridades encontrou espaço no estudo da mudança já que, com base na identificação do que é mais provável no sistema, torna-se possível, em certa medida, "prever" os rumos mais plausíveis a serem tomados no processo evolutivo das línguas.

Apesar de o problema da restrição ter sido influenciado, claramente, pela busca dos universais linguísticos que marcou os estudos de linguagem na década de 1960, não há na proposta sociolinguística a possibilidade de se pensar em mudanças que jamais ocorrerão, o que significa, diferentemente do que era assumido pela teoria gerativa, que não haveria universais invioláveis. Nas palavras de Labov (1982, p. 59): "As leis apresentadas como 'sem exceções', em um primeiro momento, parecem ser, entretanto, princípios gerais que, de fato, influenciam o curso da mudança linguística, sem com isso 
determiná-la completamente. [...] 'universal' significa 'generalização'”. ${ }^{19}$ (tradução nossa).

É com base nessa prerrogativa e a partir das generalizações feitas a partir dos estudos destinados à análise do comportamento variável da regra de concordância verbal de terceira pessoa do plural, os quais, em sua grande maioria, têm apontado a variável Saliência fônica como um forte favorecedor da marcação da pluralidade, que o grupo de fatores passou a assumir categoria de princípio geral. Scherre e Naro (2010, p. 76) afirmam que a saliência seria "o traço que governa o uso variável da concordância [...] uma categoria seguramente de natureza cognitiva $[\ldots] "$.

Apesar de existirem argumentos em prol do entendimento da saliência como um princípio geral, após a revisão das escalas (cf. Seção 1), observamos que uma restrição de ordem maior, o acento, parece fortalecer demasiadamente o peso atribuído à Saliência fônica, o que coloca em xeque também o status da variável como princípio. Isso porque o acento, um dos critérios adotados para a mensuração dos graus de saliência, especialmente na proposta de Naro (1981), trata-se de uma restrição universal visto que sílabas acentuadas são universalmente menos propícias a processos de redução/enfraquecimento/queda (VOTRE, 1978, p. 133).

Diante do fato de que a presença de acento inibe o processo de desnasalização (GUY, 1981; VOTRE, 1978) ${ }^{20}$ e, como o resultado final do processo de queda da nasalidade em verbos apontados como menos salientes corresponde ao mesmo resultado gerado pela aplicação do processo de não concordância verbal, nos parece equivocado estabelecer uma relação de causa e efeito, interpretando a saliência como categoria universal condicionadora da concordância verbal. A variável em questão, sendo assim, a nosso ver, não se trata de um princípio autêntico. Tal conclusão encontra suporte em Guy (1981):

\footnotetext{
${ }^{19}$ No original: " [...] what was proposed as excepitionaless laws at fist turn out in the end to be a genereal principles that indeed influnece the course of linguistic change without determining it absolutely. [...]'universal' means 'generalization'". (LABOV, 1982, p. 59)

20 Os estudos atuais acerca da regra de redução/desnasalização de ditongos nasais (BATTISTI, 2002; BOPP DA SILVA, 2005; SCHWINDT; BOPP DA SILVA, 2009; CRISTÓFARO-SILVA, 2012) já partem do princípio de que os processos manifestam exclusivamente em sílabas átonas, sem dedicar atenção, portanto, aos ambientes tônicos.
} 
0 acento na desinência, na verdade, é o maior componente desse efeito [de marcação explícita da concordância], já que bloqueia absolutamente a desnasalização. Mas não se trata claramente de um condicionador independente da CV [concordância verbal] (GUY, 1981, p. 268).

Além do estreito vínculo com o problema da restrição, a Saliência fônica também dialoga diretamente com o problema da avaliação. Essa relação pode ser vislumbrada na primeira formulação do conceito (NARO; LEMLE, 1976), na qual percebemos uma forte dependência do termo a um juízo de valor agregado às distinções fônicas que marcam a oposição singular/plural (cf. Seção 1). Na acepção original da variável, apontar determinadas formas verbais como mais ou menos salientes, revelava, de fato, que tais formas seriam mais ou menos perceptíveis aos sujeitos. Em outros termos, que as formas mais salientes seriam aquelas em que a não marcação da concordância seria percebida com mais destaque, o que representa que estariam acima do nível de consciência social dos falantes.

Essa constatação é fortalecida pelo caráter estigmatizado de algumas formas verbais em que a marcação explícita da concordância não é verificada. Apesar de não nos basearmos em resultados oferecidos por testes de reação subjetiva, podemos nos pautar naquilo que foi apontado por Naro e Lemle (1976) e Lemle e Naro (1977), que, em determinados contextos apontados como salientes, a não marcação da concordância verbal de terceira pessoa do plural seria estigmatizada. Situações em que o sujeito encontra-se anteposto ao verbo (Eles sai de casa); quando os verbos apresentam maior "grau de saliência" (Eles foi pra casa) e, por fim, em situações formais, são exemplos desses contextos em que a não concordância assume, em geral, avaliação negativa.

Além do resgate da concepção, é imprescindível ressaltar que não há como falar de saliência, pelo menos se continuarmos fazendo uso dessa nomenclatura, sem correlacioná-la ao problema da avaliação. Seguindo essa linha de raciocínio, alguns questionamentos, a fim de problematizar essa relação, seriam pertinentes: o que é saliente para uma comunidade é saliente para outra também? Haveria uma única escala de saliência fixa para todos os estratos sociais, todos os níveis de escolaridade e todos os estilos de emprego da fala?

Em relação à primeira indagação, ao verificarmos consonância, em alguns aspectos da hierarquia, entre os índices apresentados pelos trabalhos sobre a CVP6 em diferentes comunidades, encontramos indícios de que a saliência teria caráter estrutural, como têm argumentado as propostas oferecidas até o momento, já que a 
categoria, mensurada com base apenas em critérios puramente linguísticos, tem se mostrado relevante. No que diz respeito à segunda questão, precisaríamos cogitar novas estratégias para mensurar como os sujeitos pertencentes a determinadas comunidades de fala avaliam cada um desses graus.

\section{Considerações finais}

Este artigo, a partir da revisão crítica das diferentes acepções e propostas de medição escalares da variável Saliência fônica, adotadas pelos estudos acerca da concordância/não concordância verbal de terceira pessoa do plural no português brasileiro, atenta para algumas questões relevantes sobre o tema: (i) a necessidade de uma reflexão mais rigorosa sobre os critérios eleitos para a delimitação das diferenças fônicas entre as formas verbais singulares/plurais, levando-se em conta a intrínseca relação entre as regra de concordância e de redução e desnasalização de ditongos nasais átonos finais; (ii) a relevância dos problemas da restrição e da avaliação no direcionamento de novas propostas para a medição da saliência e na reflexão a respeito do caráter de princípio atribuído à categoria.

\section{Referências}

BATTISTI, Elisa. A redução dos ditongos nasais átonos. In: BISOL, Leda; BRESCANCINI, Cláudia (Orgs.). Fonologia e variação: recortes do português brasileiro. Porto Alegre: EDIPUCRS, 2002, p. 183-202.

CHISTÓFARO - SILVA, Thaís; FONSECA, Marco Silva; CANTONI, Maria. A redução do ditongo [ãw] postônico na morfologia verbal do português brasileiro: uma abordagem baseada no uso. Letras de Hoje, Porto Alegre, v. 47, n. 3, p. 283-292, jul./set. 2012.

HOUAISS, Antônio; VILLAR, Mauro de Sales; FRANCO, Francisco Manoel de Mello. Minidicionário Houaiss de língua portuguesa. 2. ed. Rio de Janeiro: Objetiva, 2004.

FARIA, Nicolle Veronick Moreira de. A concordância verbal no português de Belo Horizonte. 2008. 141fls. Dissertação (Mestrado em Letras) - Pontifícia Universidade Católica de Minas Gerais, Belo Horizonte, 2008.

GONÇALVES, Vânia de Fátima. A ausência de concordância verbal no Vale do Rio Doce. 2007. 121fls. Dissertação (Mestrado em Linguística) - Universidade Federal de Minas Gerais, Belo Horizonte, 2007. 
GUY, Gregory Riordan. Linguistic variation in Brazilian Portuguese: aspects of the phonology, syntax, and language history. 391fls. Tese (Doutorado em Linguística) University of Pennsylvania, Philadelphia, 1981.

LABOV, William. Building on empirical foundations. In: LEHMANN, Winfred P.; MALKIEL, Yakov (Eds.) Perspectives on historical linguistics. Amsterdam/ Philadelphia: John Benjamins, 1982.

LABOV, Wiliam. Principles of linguistic change: Internal factors. Cambridge: Blackwell, 1994.

LEMLE, Miriam; NARO, Anthony Julius. Competências Básicas do Português. Relatório Final apresentado às instituições Fundação Ford e Movimento Brasileiro de Alfabetização (Mobral), 1977.

MONGUILHOTT, Isabel de Oliveira e Silva. Variação na concordância verbal de terceira pessoa do plural na fala dos florianopolitanos. 2001. 99fls. Dissertação (Mestrado em Linguística) - Universidade Federal de Santa Catarina, Florianópolis, 2001.

. Estudo sincrônico e diacrônico da concordância verbal de terceira pessoa do plural no PB e PE. 2009. 229fls. Tese (Doutorado em Linguística)- Universidade Federal de Santa Catarina, Florianópolis, 2009.

NARO, Anthony Julius. The social and structural dimensions of a syntatic change. LSA, Language, v. 57, p. 63-98, 1981.

; LEMLE, Miriam. Syntatic diffusion. In: STEEVER, Sandord B. et alii (Eds.) Papers from the parasession on Diachronic Syntax. Chicago: Chicago Linguistic Society, p.221241, 1976.

; SCHERRE, Maria Marta Pereira. Origens do Português Brasileiro. São Paulo: Parábola Editorial, 2007.

NICOLAU, Eunice Maria das Dores. A Ausência de Concordância Verbal em Português: uma abordagem sociolingüística.1984. 196fls. Dissertação (Mestrado em Letras)Universidade Federal de Minas Gerais, Belo Horizonte, 1984.

A influência da constituição morfológica da forma verbal na ausência de concordância em Português.Revista de Estudos da Linguagem. Belo Horizonte: UFMG, ano IV, n. 3, v. 2, p. 41-67, 1995.

SANTOS, Camila Patrícia dos. A concordância verbal na mídia radiofônica de Belo Horizonte. 2013. 114fls. Dissertação (Mestrado em Letras)- Pontifícia Universidade Católica de Minas Gerais, Belo Horizonte, 2013.

SCHERRE, Maria Marta Pereira; NARO, Anthony Julius. Efeitos da saliência fônica e do tempo/modo na concordância verbal. In: MOLLICA, Maria Cecília de Magalhães (Orgs.).Usos da linguagem e sua relação com a mente humana. Rio de Janeiro: Tempo Brasileiro, p. 71-77, 2010.

VOTRE, Sebastião Josué. Aspectos da variação fonológica na fala dos analfabetos do Rio de Janeiro.1978. 202fls. Tese (Doutorado em Letras) - Pontifícia Universidade Católica do Rio de Janeiro, 1978. 
WEINREICH, U.; LABOV, W.; HERZOG, M. Fundamentos empíricos para uma teoria da mudança lingüística. Trad. de Marcos Bagno. São Paulo: Parábola, 2006 [1968].

WELCHEN, Dirce. Pelotas e a concordância verbal de 3a pessoa de plural. 2009. 150fls. Tese (Doutorado em Letras) - Universidade Federal do Rio Grande do Sul, Porto Alegre, 2009.

Recebido em junho de 2014.

Aceito em setembro de 2014. 